\title{
Using the Theory of Institutional Isomorphism to Create a Conceptual Framework of the Governance of Clinical Research in Relation to National Mutual Acceptance
}

\author{
Bernice Davies \\ Victoria University, Australia
}

\begin{abstract}
The objective of this paper is to develop a conceptual framework, based on the corporate governance theory of institutional isomorphism, to explain key drivers of the varied research governance practices in Victorian hospitals in relation to the newly introduced National Mutual Acceptance (NMA). The paper commences with a brief discussion of the clinical and economic importance of clinical research. This is followed by a conceptualisation of four pillars in research governance. The following step overlays the constructs of institutional isomorphic theory: organisational legitimacy, organisational fields and the mechanisms of coercive, mimetic and normative isomorphism, on the governance pillars. This conceptual crossover identifies potential areas that, in addition to regulatory obligations, may influence the level of organisational engagement with NMA objectives. In so doing the model provides meaning and significance to different corporate approaches to the governance of clinical research in organisational address of the implications of the National Mutual Acceptance
\end{abstract}

\section{Keywords}

Foreign Direct Investment, Democracy, Panel Data

\section{Aim}

The objective of this paper is to develop a conceptual framework, based on the corporate governance theory of institutional isomorphism, in order to explain the key drivers behind research governance practices developed by Victorian hospitals in relation to the newly introduced National Mutual Acceptance (NMA).

\section{Background}

National Mutual Acceptance (NMA) is a national system of single scientific and ethical review of multi-centre clinical trials conducted in publicly funded health services. It was introduced by the Australian Commonwealth Government (2012) to help reduce the costs and time taken to approve trials that were to be undertaken at multiple sites. The specific goal of the NMA is that the ethical and scientific review is completed in 60 days. Single review means that an approval from an accredited ethics committee (National Health and Medical Research Council, 2014) anywhere in Australia can

Copyright (C) 2015 Victoria University. This document has been published as part of the Journal of Law and Governance in both online and print formats. Educational and non-profit institutions are granted a non-exclusive licence to utilise this document in whole or in part for personal or classroom use without fee, provided that correct attribution and citation are made and this copyright statement is reproduced. Any other usage is prohibited without the express permission of the publisher. be accepted by all affiliated public hospitals. The hospital, however, is then responsible for ensuring that it has the capacity to undertake the trial through a process termed site specific assessment. This assessment involves consideration of such matters as resources, staff, insurance, indemnity requirements and that the roles and responsibilities of all parties are clearly delineated. Research governance 
involves the processes, customs, policies, laws, management practices and institutions affecting the way research is controlled and managed. An appropriate organisational research governance framework incorporates these factors in order to meet the goals of responsible research practices in the most effective and efficient manner possible (Commonwealth of Australia, 2007). Effective corporate governance strategy enables an organisation to manage all aspects of its business in order to meet its objectives (ASX Corporate Governance Council, 2007). Research governance is a subset of corporate governance and hence a part of the individual organisation's governance strategy but there is also a need to establish consistency in this area especially for those projects approved through single ethical review (National Health and Medical Research Council, 2011).

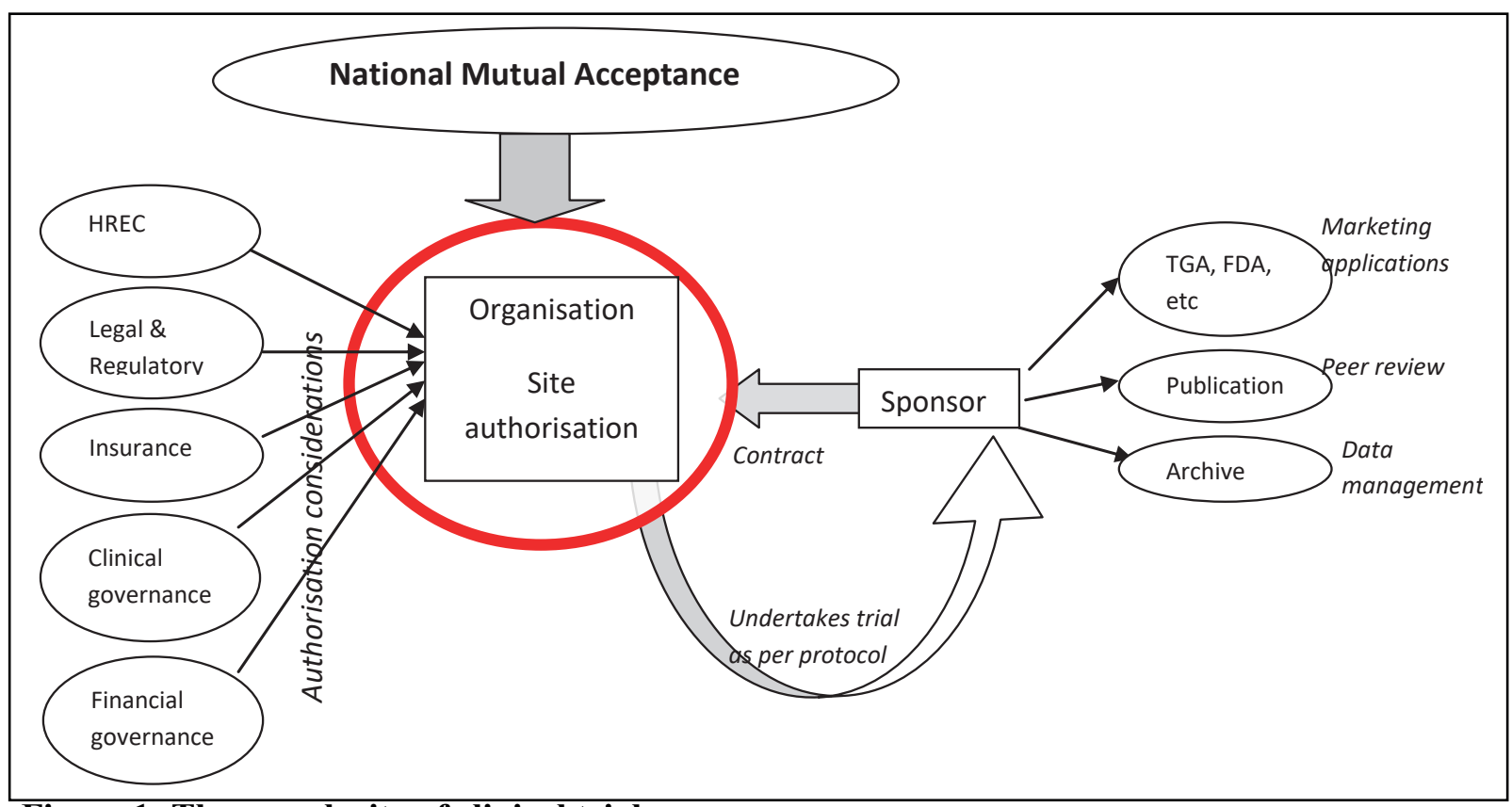

Figure 1: The complexity of clinical trial governance

Governance of clinical research and trials presents a number of challenges to scholars especially if the project involves more than one site. Figure 1 provides an overview of the diverse stakeholders involved in undertaking clinical research. Each stakeholder has specific requirements, which may not always converge with other stakeholders. For example, the trial sponsor may urge for prompt contract resolution, but agreement may be constrained by specific clinical practices, such as number of available inpatient bed days, which may require further negotiation.

Although a full analysis of all the stakeholder requirements is beyond the scope of this paper, it will, however, focus specifically research governance in relation to the NMA.

\section{Why study research governance?}

Proponents of clinical trials list many advantages to hospitals being involved with clinical trials such as clinical and financial returns. They emphasise that clinical trials provide the critical link between new clinical discoveries and population health, as indicated in Figure 2 below.
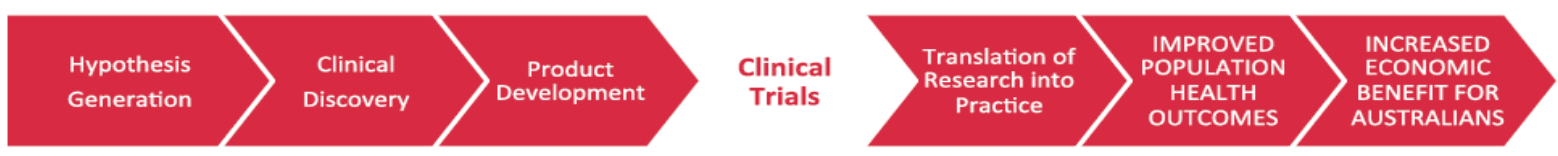

Figure 2: Critical role of clinical trials in clinical 'pipeline' (Australian Clinical Trial Alliance, 2014, p. 3) 
They argue that clinical advantages include access to innovative treatments not yet available to the general public; professional benefits to study staff; and that hospitals undertaking the trial are able to access free clinical treatment for their patients (Advisen Insurance Intelligence, 2012; Australian Clinical Trial Alliance, 2014; Bourgeois; Medicines Australia, 2011).

Other proponents note the financial advantages. Global investment in research and development has been estimated at $\$ 1.6$ trillion and attracting commercial investment has become very competitive (Battelle, 2014). Within Australia, it is estimated that the medicines industry invests over $\$ 1$ billion in research and development every year and over 14,000 people are directly employed in the sector (Research Australia, 2011). However, recent changes in the clinical research landscape indicate that Australia may not be in a position to command this investment into the future (Campion \& Engwall, 2013).

Globally clinical research, especially the clinical trials, has entered an era of unprecedented change and challenge as breakthroughs in biomedical sciences, such as human genomics, combined with commercial requirements for fast results, have resulted in multicentre research (that is, research which is simultaneously undertaken at many sites) becoming more common. At the same time, multicentre research, especially commercial clinical trials are relocating from the traditional Western research markets (Sung et al., 2003) into areas such as Asia, which offers large target populations (Battelle, 2014; Clark, 2009). Hence, the timeliness of research governance has been the subject of recent worldwide debate and discussion (Campion \& Engwall, 2013; Manville, Hackett, Gunashekar, \& Morgan Jones, 2013). Specifically, single ethics review and separation of site specific review process from the ethics review are being adopted in order to undertake ethical and site considerations simultaneously. There are varying levels of regulatory control supporting the process. The USA and the UK, for example, have both adopted highly regulated governance frameworks (Howarth, Kneafsey, \& Haigh, 2008; Manville et al., 2013). However in Australia there is no authority to force the uptake of mutual acceptance or centralised model of ethics review (Breen, 2005). Hence, in Australia the extent to which hospitals have complied with benchmark expectations for rapid review of multicentre clinical research varies (Hasthorpe, 2014).

The concept of research governance is a relatively new area and the literature is limited. The concept does not fit neatly with existing health care clinical and financial governance practices (Victorian Department of Health, 2008). However, there is data indicating that organisations engaged with the NMA, where the concept of research governance is central, are failing to consistently reach target approval times (Hasthorpe, 2014). Hence, there is a critical gap in understanding the influences on organisation behaviour in research governance.

\section{Research reform in Australia}

By the mid-2000's, pharmaceutical and research lobbyists had identified a 'four pillar' approach to improve Australia's attraction as a clinical trial environment (National Museum of Australia, 2006). The four interconnected pillars were identified as timeliness quality, value and capacity. Table 1 provides the key attributes of each pillar and examples of organisational behaviour that indicate support of the pillars. 
Table 1: Attributes of corporate research governance in relation to the four pillar model

\begin{tabular}{|l|l|l|}
\hline Pillar & Key attribute & Evidence \\
\hline Timeliness & $\begin{array}{l}\text { Single ethics } \\
\text { review }\end{array}$ & $\begin{array}{l}\text { Regulatory compliance } \\
\text { NMA benchmark performance e.g. speed of review }\end{array}$ \\
\hline Quality & Excellence & $\begin{array}{l}\text { Research strategy indicating research is a core hospital activity } \\
\text { Certification programs e.g. formal HREC accreditation, certification of } \\
\text { researchers qualification, standard position descriptions }\end{array}$ \\
\hline Value & Costs & $\begin{array}{l}\text { Use of standardisation /centralisation e.g. research agreements, service } \\
\text { costs } \\
\text { Research strategy is in keeping with research guidelines (codes/ } \\
\text { legislation/ government direction) }\end{array}$ \\
\hline Capacity & Competence & $\begin{array}{l}\text { Recruitment capability } \\
\text { Transparent organisational research strategy } \\
\text { Profile of organisational research } \\
\text { Audit and reporting systems }\end{array}$ \\
\hline
\end{tabular}

Timeliness has been identified as the critical factor in the success of clinical research projects, to ensure that projects remain in budget and that study data is made available promptly (National Museum of Australia, 2006; NSW Ministry of Health, 2013). However, while timeliness centres on improving time to project start-up by employing a model of single ethics review, start-up speed also depends on the effectiveness of the other pillars. Quality in research is indicated through evidence of education such as training in Good Clinical Practice (GCP), formal accreditation of human research ethics committees and standards for scientific and ethical review. Value refers to efforts to minimise costs and increase transparency of negotiation, hence the development of the National Efficient Price for a list of standard items associated with conducting Clinical Trials( (Independent Hospital Pricing Authority (IHPA), 2013). Capacity refers to the competence of the research site in reaching target while adhering to protocol. In particular, this refers to recruitment strategies (Clinical Trial Action Group, 2011).

\section{0 day benchmark of the National Mutual Acceptance (NMA)}

The primary aim of the NMA is to limit the time taken for scientific and ethical review and decision by applying a 60 calendar day benchmark. Victoria has further qualified the NMA benchmark to 30 working days for ethical review undertaken by Victorian HRECs (Victorian Department of Health, 2013). However, recent Victorian data indicates that, despite extensive support and guidance for those involved with the NMA, there remains considerable variation in times to full research authorisation (Hasthorpe, 2014).

\section{Theoretical basis: Institutional Isomorphism Theory}

The model is based on the corporate governance theory of Institutional Isomorphism, through the organisation is viewed as a social entity that desires to appear legitimate in its social circle. Isomorphism occurs when the structure or processes of one organisation develops similarity to another. This is driven less by the desire for efficiency but the desire to appear to be behaving in a legitimate or appropriate manner (DiMaggio \& Powell, 1983). The theory rests three closely connected mechanisms; coercive, mimetic and normative. 


\section{Organisational legitimacy}

Organisational legitimacy is a critical but somewhat abstract concept that has been defined as a 'generalized perception or assumption that the actions of an entity are desirable, proper, or appropriate within some socially constructed system of norms, values, beliefs, and definitions' (Suchman, 1995, p. 574). It is conferred by those outside the organisation who have legitimacy-determining power (Pfeffer \& Salancik, 1978) but it is also dynamic, reflecting the needs of organisations to perpetuate acceptance in a changing society.

\section{Organisational fields}

Organisational fields are defined as 'sets of organizations that, in the aggregate, constitute a recognized area of institutional life; key suppliers, resource and product consumers, regulatory agencies, and other organizations that produce similar services or products' (DiMaggio \& Powell, 1983, p. 148). The concept is elemental in institutional isomorphic theory, as it defines and delimits the activities of the organisations and other social actors within that field (Machado-da-Silva, Guarido Filho, \& Rossoni, 2006).

\section{Mechanisms of isomorphism}

Three key mechanisms have been identified: coercive isomorphism, mimetic isomorphism and normative isomorphism.

Coercive isomorphism is that which stems from political influence and by the cultural expectations of legitimacy of the society in which the organisation functions(DiMaggio \& Powell, 1983). For example, in order to participate in the National Mutual Acceptance (NMA), hospitals are required to use the specified software and appoint a dedicated role, the Research Governance officer (RGO).

Mimetic isomorphism refers to an organisation's response to uncertainty by copying others That is, the pressure to copy or emulate the activities, systems, or structures of other organisations, is particularly strong in times when goals are ambiguous or when organisational technologies are poorly understood (DiMaggio \& Powell, 1983). In this situation, mimicking another organisation, which is perceived as successful or legitimate, becomes a 'safe' way to proceed. Such mimicry also helps to preserve the status quo among comparable organisations, stabilising the leader relative positions while raising the possibility of failure for those that at differently. In other words, an organisation conforms to strategic behavioural norms to in order to demonstrate that it is acting in an acceptable manner and that social actors should evaluate it as legitimate (Meyer \& Rowan, 1977).

Normative isomorphism is associated with professionalization, that is, pressures brought about by a profession establishing a cognitive base and legitimisation (DiMaggio \& Powell, 1983). This can be through formal education or professional networks that span organisations so that the end result is that personnel from similar backgrounds will approach problems in much the same way.

While there is some overlap between the three mechanisms, they derive from different conditions. Mimetic and normative processes derive from internal drivers, whereas coercive isomorphism is linked to the environment surrounding the organisational field (Frumkin \& Galaskiewicz 2004). It could reasonably be expected that the dominant isomorphic mechanism in public health care organisations would be coercive. Coercive pressures can be seen clearly in the NMA through the use of memorandums of understanding between parties which explain organisational responsibilities as the use of benchmark targets (Victorian Department of Health, 2014). Literature, however, has found that government organisations are susceptible to other isomorphic influences (Frumkin \& Galaskiewicz 2004) and that responses to coercive influence can vary (Ashworth, Boyne, \& Delbridge, 2007). Hence, the proposed model includes coercive, mimetic and normative isomorphism. 


\section{Logistical basis to legitimacy}

Figure 3, below, unpacks the connection between isomorphic theory and the intended outcome of legitimacy. Legitimacy may be attained though one or more endorsements: government, public or professional endorsement. It is important to note that one endorsement does not automatically imply others. In other words, an organisation could achieve legitimacy, such as government endorsement if it fulfilled compliance requirements, but difficulties may arise if such compliance was achieved using processes and structures that were not in keeping with peers. For example, an organisation that required vastly different research application forms than other hospitals might be avoided if this meant that research applications absorbed more time and resources than equitable applications elsewhere.

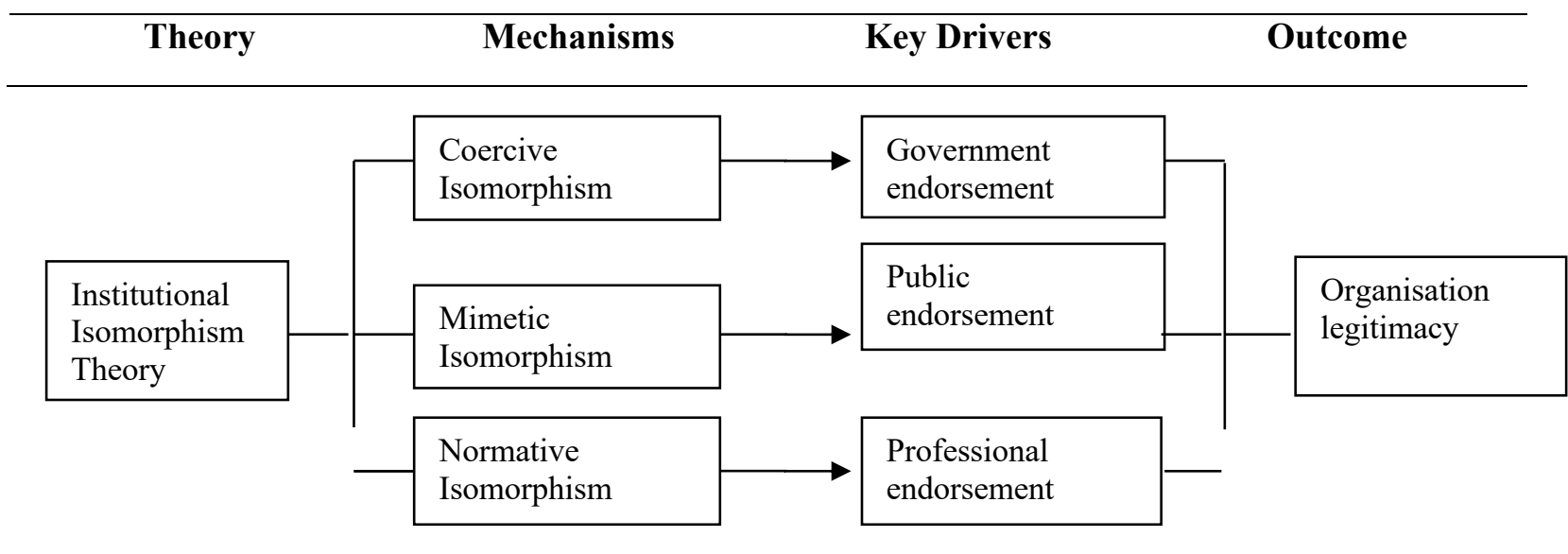

Figure 3: Logistics of isomorphic theory leading to legitimacy

\section{Conceptualisation of a the research governance model}

Drawing on the data from Table 1 and the connections outlined in Figure 3, the next step was to create a conceptual crossover of isomorphic theory and single ethical review (Figure 4) through which the organisation's Board of Directors stratagem is linked to drivers of organisational legitimacy.

Figure 4 demonstrates the isomorphic mechanics that connect corporate strategy to endorsement of the NMA as a legitimate outcome. Governance endorsement of legitimacy is driven by coercive isomorphism to achieve timeliness. Public endorsement is driven by mimetic isomorphism to address stakeholder perception of organisational value and capacity. Professional endorsement is driven by normative isomorphism to achieve perceptions of quality. However, as indicated in the model, hospital demographics and characteristics of the Board of Directors may also impact significantly on the level of endorsements. 


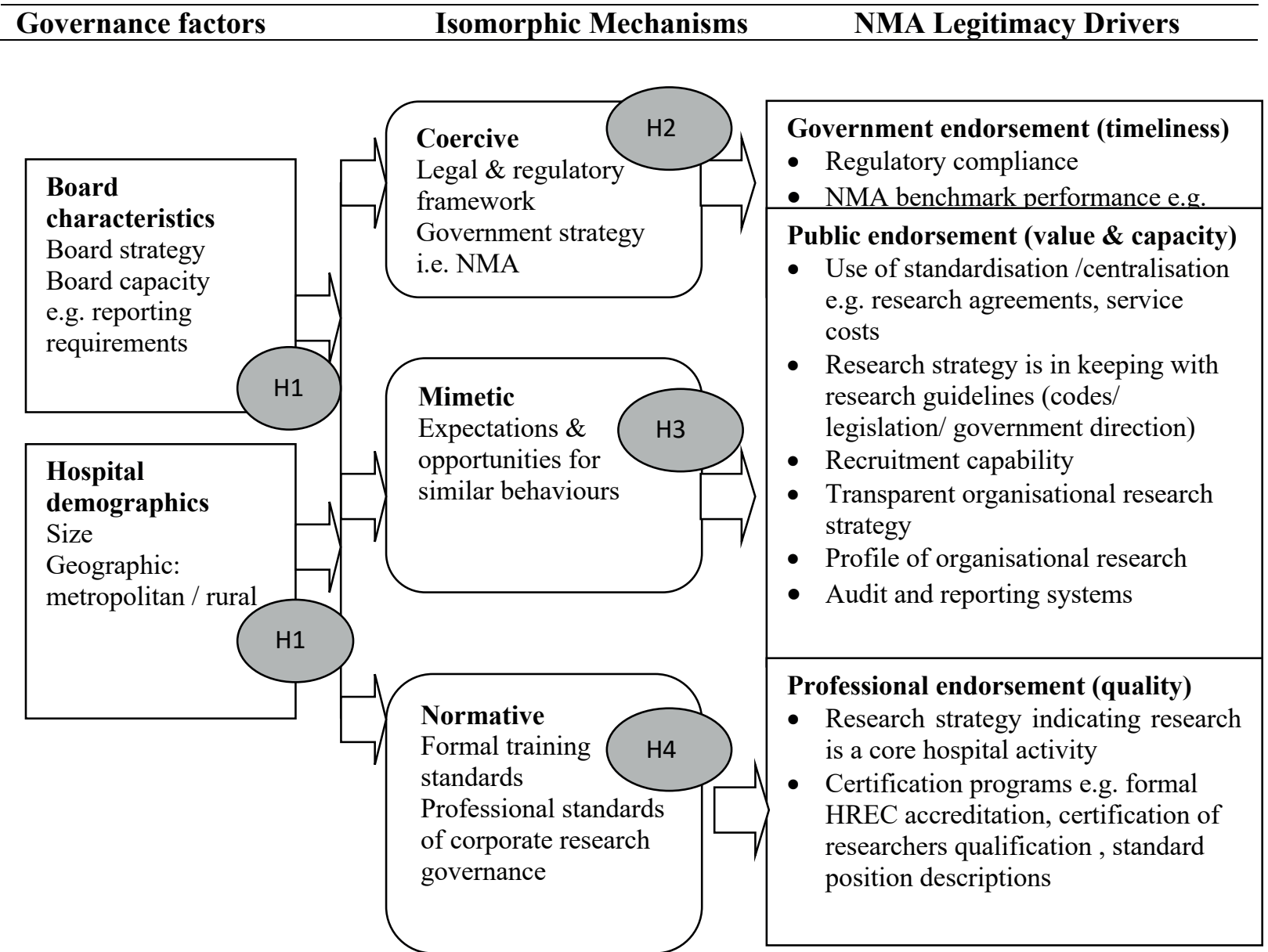

Figure 4: The conceptual crossover of isomorphic theory and single ethical review

\section{Development of the hypotheses}

The main research question leading to the development of this model asks 'what practices in corporate governance of clinical research best address the implications of the National Mutual Acceptance?' which led to the development of the following hypotheses.

\section{Summary of Hypotheses}

The hypotheses developed in this study are based on the belief that the greater degree to which hospitals recognise research as a core activity will have a positive impact on the compliance with the National Mutual Acceptance.

\section{Organisational legitimacy}

Literature suggests that organisational survival depends not just on material resources and technical information, but also on the organisation being perceived as acceptable and credible, or in other words, legitimate (DiMaggio \& Powell, 1983). Currently governance of research is not included in health service governance (Victorian Department of Health, 2008) and the degree to which public hospitals comply with the NMA benchmarks is not consistent (Hasthorpe, 2014). The inference is that 
there is a variation in the perception of value of research in hospitals. Thus, we expect that the degree to which research is viewed as a core hospital activity is expected to provide the strongest predictor of NMA compliance and remain significant at all other points of measurement.

H1(a): The extent to which research is regarded as a core hospital activity is positively associated with the perceived importance of formalising corporate research governance strategy

Drawing from the above arguments, the relevance of the NMA to change in the public hospitals may depend on organisational characteristics. Thus we propose that dependency will be most salient for those metropolitan organisations with a large clinical research division.

H1(b): The extent to which research is regarded as a core hospital activity will be moderated by organisational demographics, particularly geographic location and size of the research division.

\section{Organisational dependence}

Organisations depend on stakeholders to acknowledge them as more 'meaningful, predictable, and trustworthy' (Suchman, 1995, p. 575). Stakeholders proffer or withhold their support in return for the organisation producing an output valued by the stakeholder (goods and/or services). Hence organisations depend on stakeholders for survival. The key isomorphic mechanism is coercive. Within the context of public health, the dominant stakeholder in coercive isomorphism is generally seen as government but in this research context, stakeholders also include research sponsors such as commercial companies whose withdrawal from a site may have profound financial or clinical implications.

H 2: $\quad$ The extent to which hospitals depend upon the NMA, is positively associated with higher level of coercive isomorphism

\section{Managing uncertainty}

Mimetic isomorphism is the mechanism whereby organisations model themselves on other organisations in order to gain legitimacy when the environment is uncertain (DiMaggio \& Powell, 1983). Such mimetic behaviour is rational because it conserves search costs to reduce the uncertainty being faced by the organisation (Meyer \& Rowan, 1977). The nature of clinical research has become very complex, characterised by numerous stakeholders and increasingly involved regulatory requirements. Currently, compliance to the NMA cannot be enforced leading to variations in the subsequent behaviour.

Hypothesis 3: The extent to which the environment is regarded as uncertain is positively associated with hospitals adopting similar structure and processes

\section{The impact of professionalization}

The degree to which normative isomorphism, or pressures from professionalization and formal training, affects organisational behaviours has been much promoted in institutional isomorphism theory (DiMaggio \& Powell, 1983; Meyer \& Rowan, 1977). Theorists argue that people from the same educational backgrounds will approach problems in similar ways. In other words, interorganisational socialization such as professional networks or inter-organisational hiring will reinforce norms and routines.

Research administrators a recruited from a variety of backgrounds but traditionally there has been a lack of clear boundaries and role definitions (Dunscombe, 2008). Currently there is no standardised position description or career path, but the state government offers limited networking opportunities(Victorian Department of Health, 2015). 
Hypothesis 4: The extent to which to which the field is professionalised is positively associated with greater isomorphism

\section{Conclusion}

Determining organisational behaviour in relation to the NMA is a novel area of academic pursuit. This paper presented a conceptual framework, based on the institutional isomorphism theory, in order to explain the key drivers or mechanisms behind Victorian hospitals research governance practices developed in relation to the NMA. Following from the crossover of the institutional isomorphism theory with the key terms of single ethical review presented here, it is proposed that research should now focus on identifying such constructs that can add to the prediction of organisational behaviour over and above what is already known. The present work will advance institutional isomorphism research by developing the theoretical perspectives to account for dynamic influences on organisation behaviours in the governance of research.

\section{References}

Advisen Insurance Intelligence. (2012, ). Clinical trial research in hospitals. Retrieved 21/07, 2014, from http://www.acegroup.com/us-en/assets/advisen_clinicaltrialresearchinhospitals.pdf

Ashworth, R., Boyne, G., \& Delbridge, R. (2007). Escape from the Iron Cage? Organizational Change and Isomorphic Pressures in the Public Sector. Journal of Public Administration Research and Theory, 19(1), 165-187. doi: 10.1093/jopart/mum038

ASX Corporate Governance Council. (2007). Corporate Governance principles and recommendations (2nd Edition ). http://galres.com/documents/ASXCorporateGovernancePrinciples_000.pdf

Australian Clinical Trial Alliance. (2014). ACTA submission to the Senate Inquiry into Australia's Innovation System. from http://www.clinicaltrialsalliance.org.au/wpcontent/uploads/2014/08/ACTA_Submission_Innovation_Inquiry_126.pdf

Battelle. (2014). 2014 Global R\&D Funding Forecast $R \& D$ Magazine. http://www.battelle.org/docs/tpp/2014 global rd funding forecast.pdf?sfvrsn=4

Bourgeois, C. Value of Industry Sponsored Clinical Trials in Australia.Inaugural Survey of Investigator Perceptions on the Value of Industry Funded Clinical Research. Retrieved 23/11/2014, from http://www.pharmacouncil.com.au/news_pdfs/Value $\% 20 \mathrm{of} \% 20$ Industry $\% 20$ Sponsored $\% 20 \% 20$ Clinical\%20Trials\%20in\%20Australia\%20-\%20Report $\% 20$ on $\% 20$ the $\% 20$ Inaugural $\% 20$ Survey $\% 20$ of $\% 20 \% 20$ Investigator $\% 20$ Perceptions $\% 20$ on $\% 20$ the $\% 20$ Value $\% 20$ of $\% 20$ Industry\%20Funded\%20Clinical\%20\%20Research.pdf

Breen, K. J. (2005). Multi-centre Clinical Trials: Issues around Ethical and Scientific Review. Paper presented at the Inter-jurisdictional Forum: Towards timely, efficient and effective review of multi-centre clinical trials, Sydney http://www.nhmrc.gov.au/ files nhmrc/file/health ethics/ homer/inter-jurisdictionalforum-feb-2005.pdf

Campion, K., \& Engwall, D. (2013 ). Improving Research Governance: ARCS Australia Clinical Research Governance Forum Outcomes Paper Feb 2013. In ARCS Australia (Ed.). Sydney.

Clark, T. D. (2009). The Case for Globalization: Ethical and Business Considerations in Clinical Research. Retrieved 31/01/2015, from http://www.acrohealth.org/wpcontent/uploads/2014/09/Case-for-Globalization_FINAL.pdf

Clinical Trial Action Group. (2011). Clinically competitive:boosting the business of clinical trials in Australia. http://www.industry.gov.au/industry/PharmaceuticalsandHealthTechnologies/Clinical TrialsActionGroup/Documents/Clinical_Trials_Action_Group_Report.pdf

Commonwealth Government. (2012). Communique : 10 August 2012. Canberra

Commonwealth of Australia. (2007). Australian Code for the Responsible Conduct of Research. Canberra, Australia: Commonwealth of Australia Retrieved from https://www.nhmrc.gov.au/ files nhmrc/publications/attachments/r39.pdf.

DiMaggio, P. J., \& Powell, W. $\bar{W}$. (1983). The iron cage revisited: Institutional isomorphism and collective rationality in organizational fields. American Sociological Review, 48(147-60.). 
Dunscombe, K. (2008). How do human research ethics committee administrators see and manage their role in the ethical review process? (Master of Social Health (Health Ethics) Minor), The University of Melbourne, Melboune. Retrieved from http://chs.unimelb.edu.au/_data/assets/ pdf_file/0011/787124/Merged_PDF_file_of_KD thesis_for_Web.pdf

Frumkin, P., \& Galaskiewicz , J. (2004). Institutional isomorphism and public sector organizations. Journal of Public Administration Theory, 14(3), 283-307.

Hasthorpe, S. (2014). Victorian overview: regulatory process data for clinical trials. Retrieved 26/01/2015, from http://docs.health.vic.gov.au/docs/doc/Suzanne-Hasthorpe-Presentationdec 2014

Howarth, M., Kneafsey, R., \& Haigh, C. (2008). Centralization and research governance: does it work? . Journal of Advanced Nursing, 61(4), 363-372.

Independent Hospital Pricing Authority (IHPA). (2013). Development of a table of standard costs for conducting Clinical Trials in Australia: final report. Retrieved 18/01/2015, from http://www.ihpa.gov.au/internet/ihpa/publishing.nsf/Content/clin-trials-standard-cost-2013.htm

Machado-da-Silva, C. L., Guarido Filho, E. R., \& Rossoni, L. (2006). Organizational Fields and the Structuration Perspective: Analytical Possibilities. Brazilian Administration Review, 3(3), 32-56. http://www.anpad.org.br/bar

Manville, C., Hackett, P. J., Gunashekar, S., \& Morgan Jones, M. (2013). Regulatory cultures and research governance. http://www.rand.org/content/dam/rand/pubs/research_reports/RR200/RR234/RAND_RR234.pdf

Medicines Australia. (2011). Keeping clinical trials in Australia; why action is needed now Occasional Paper, Series 3. from http://medicinesaustralia.com.au/files/2011/02/OccasionalPaper-3-Clinical-Trials.pdf

Meyer, J. W., \& Rowan, B. (1977). Institutionalized Organizations: Formal Structure as Myth and Ceremony. American Journal of Sociology, Vol. 83, No. 2 (Sep., 1977), pp., 83(2), 340-363.

National Health and Medical Research Council. (2011). Research Governance Handbook: Guidance for the national approach to single ethical review. Canberra: Commonwealth of Australia Retrieved from http://hrep.nhmrc.gov.au/_uploads/files/research_governance handbook.pdf.

National Health and Medical Research Council. (2014). Human Research Ethics Portal. Retrieved 01/01/2015, from https://hrep.nhmrc.gov.au/national-approach

National Museum of Australia, C. (2006). Report on the Forum on a National Approach to Clinical Trials. Retrieved 21/02/2015, from http://www.pharmacouncil.com.au/news_pdfs/Clinical_Trials_Forum_Report_20062006071411 2947.pdf

NSW Ministry of Health. (2013). Health and Medical Research Governance Project Reform of the research pre-approval process Sydney: Office for Health and Medical Research, Retrieved from http://www.health.nsw.gov.au/ethics/Documents/discussion-paper-ethics-and-governancepaper.pdf.

Pfeffer, J., \& Salancik, G. R. (1978). The external control of organisations: resource dependence perspective. New York: Harper \& Row.

Research Australia. (2011). Shaping Up: Trends and Statistics in Funding Health and Medical Research. Occasional Paper Series: Two. Retrieved 08/02/2015, from http://www.researchaustralia.org/documents/item/125\%E2\%80\%8E

Suchman, M. C. (1995). Managing legitimacy: Strategic and institutional approaches. Academy of Management Review, 20(3), 571-610.

Sung, N. S., Crowley, W. F., Genel, M., Salber, P., Sandy, L., Sherwood, L. M., Rimoin, D. (2003). Central Challenges Facing the National Clinical Research Enterprise. JAMA, 289(10), 1278. doi: 10.1001/jama.289.10.1278

Victorian Department of Health. (2008). Victorian clinical governance policy framework. Melbourne: Victorian Government Department of Human Services, Retrieved from http://docs.health.vic.gov.au/docs/doc/4C6559130DA88FD5CA257902000D5EFA/\$FILE/clin_g ov_pol_framework.pdf.

Victorian Department of Health. (2013). National Mutual Acceptance of scientific and ethical review for multi-centre clinical trials conducted in public health organisations. 